\title{
The effect of ouabain on membrane potential and flagellar wave in ejaculated bull spermatozoa
}

\author{
Angele McGrady \\ Department of Physiology, Medical College of Ohio, C.S. No. 10008, \\ Toledo, Ohio 43699, U.S.A.
}

\begin{abstract}
Summary. Ejaculated bull spermatozoa were exposed to various concentrations of ouabain to ascertain the effect on membrane potential, intracellular concentrations of sodium and potassium and motility. Membrane potential, measured by electrophysiological methods, decreased. Intracellular potassium decreased and intracellular sodium increased. Progressive motility decreased. In addition, the motility change produced by ouabain was identified as a decrease both in beat frequency and in wave amplitude.
\end{abstract}

\section{Introduction}

Previous reports (McGrady \& Nelson, 1972, 1973) have shown that membrane potential in bull spermatozoa is primarily determined by the ratio of intracellular to extracellular potassium and influenced to a lesser degree by sodium and chloride. Amplitude of the flagellar wave was found to be directly related to membrane potential (McGrady \& Nelson, 1973). However, Lindeman \& Rikmenspoel (1971) found no relationship between membrane potential and extracellular potassium in bull spermatozoa and therefore postulated the existence of a fixed charge system.

Bull spermatozoa contain several cation-dependent ATPases, which are involved in flagellar contractile processes (Nelson, 1954) and in cation transport (Quinn \& White, 1968). For example, $\mathrm{Na}^{+}-\mathrm{K}^{+}$-activated $\mathrm{Mg}^{2+}$-dependent ATPase is believed to be responsible for maintenance of the intracellular balance of sodium and potassium (Uesugi \& Yamazoe, 1966). Bull spermatozoa maintain high intracellular potassium and low intracellular sodium concentration relative to their surrounding media (O'Donnell, 1969). The extracellular concentration of these ions in large part determines the intracellular concentration (McGrady \& Nelson, 1973). The cardiac glycoside ouabain, an inhibitor of cardiac $\mathrm{Na}^{+}-\mathrm{K}^{+}$ATPase (Brody, 1974), has been shown to bind to $\mathrm{Na}^{+}-\mathrm{K}^{+}$-activated ATPase sites in the midpiece-tail of bull spermatozoa (O'Donnell \& Ellory, 1970). As part of our efforts to investigate the permeability properties of mature and developing spermatozoa, the present study of freshly ejaculated bull spermatozoa considered the effect of ouabain on membrane potential, frequency of the flagellar beat and maximum amplitude of the flagellar wave in order to (a) determine the contribution of ouabainsensitive $\mathrm{Na}^{+}-\mathrm{K}^{+}$transport to membrane potential in bull spermatozoa, and (b) clarify the effects of ouabain on specific characteristics of motility.

\section{Materials and Methods}

The sperm suspension was prepared by diluting fresh semen $1: 3(\mathrm{v} / \mathrm{v})$ with the following medium (Mann, 1964): $500 \mathrm{mg}$ fructose, $23.9 \mathrm{mg} \mathrm{NaHCO}, 19.2 \mathrm{mg} \mathrm{NaH} \mathrm{PO}_{4}, 38.4 \mathrm{mg}$ $\mathrm{MgSO}_{4} \cdot 7 \mathrm{H}_{2} \mathrm{O}, 42 \cdot 2 \mathrm{mg} \mathrm{KCl}, 820.8 \mathrm{mg} \mathrm{NaCl}$ per $100 \mathrm{ml}$ glass-distilled water, buffered at $\mathrm{pH}$ 7.3. Total potassium was $7.3 \mathrm{~mm}$ and total sodium was $143 \mathrm{~mm}$. All experiments were conducted at room temperature $\left(23 \pm 0.5^{\circ} \mathrm{C}\right)$. 
The cell suspension was centrifuged for $10 \mathrm{~min}$ at $400 \mathrm{~g}$, and the cells were re-suspended in Mann's medium (control) or in Mann's medium with various concentrations of ouabain and incubated for up to $30 \mathrm{~min}$. To facilitate the electrophysiological and cinematographic measurements, $1.5 \%$ methyl cellulose was added to the control and ouabain-modified media. The heads of actively flagellating spermatozoa were impaled with glass microelectrodes of 15-60 M $\Omega$ resistance as reported previously (McGrady \& Nelson, 1972, 1973). Membrane potential determinations were averaged over 5-min intervals. Calculations of the wave characteristics, maximum amplitude of the flagellar wave and beat frequency were made from developed film strips with an analyser projector (Lafayette). The progressive motility was defined as the number of cells (expressed as \%) moving forward in a given population. Intracellular and extracellular ion determinations of sodium and potassium were carried out by flame photometry as reported previously (McGrady \& Nelson, 1973). No corrections were made for extracellular space.

\section{Results}

Text-figure 1 shows the effect over time of three concentrations of ouabain on membrane potential in freshly ejaculated bull spermatozoa. The membrane potential in the control solution averaged $-8.0 \pm 0.23 \mathrm{mV}$ (mean \pm s.e.m.) and remained unchanged over the 30 -min period, and these values confirm those originally reported by McGrady \& Nelson (1972). When the cells were suspended in Mann's medium with $10^{-6}$ M-ouabain, the membrane potential declined slightly during the first $5 \mathrm{~min}$, reached a plateau, then declined further at $20 \mathrm{~min}$ to stabilize at $-5.6 \pm 0.4 \mathrm{mV}$. In medium with $10^{-4} \mathrm{M}$-ouabain, the membrane potential declined rapidly to $-4 \mathrm{mV}$ within the first $10 \mathrm{~min}$ but then remained stable. A similar decrease occurred with $10^{-3}$ M-ouabain but the plateau value was $-3.5 \mathrm{mV}$. When membrane potential was plotted against ouabain concentration a regression line with a slope of -1.14 was obtained, with the slopes of arbitrarily determined points along the line differing by less than $3 \%$. When the straight line equation $y=\mathrm{m} x+b$ was used to compare obtained and predicted values, the variability was $<1 \%$. Thus the relationship between average membrane potential and ouabain concentration was linear (with a correlation coefficient of 0.995 ).

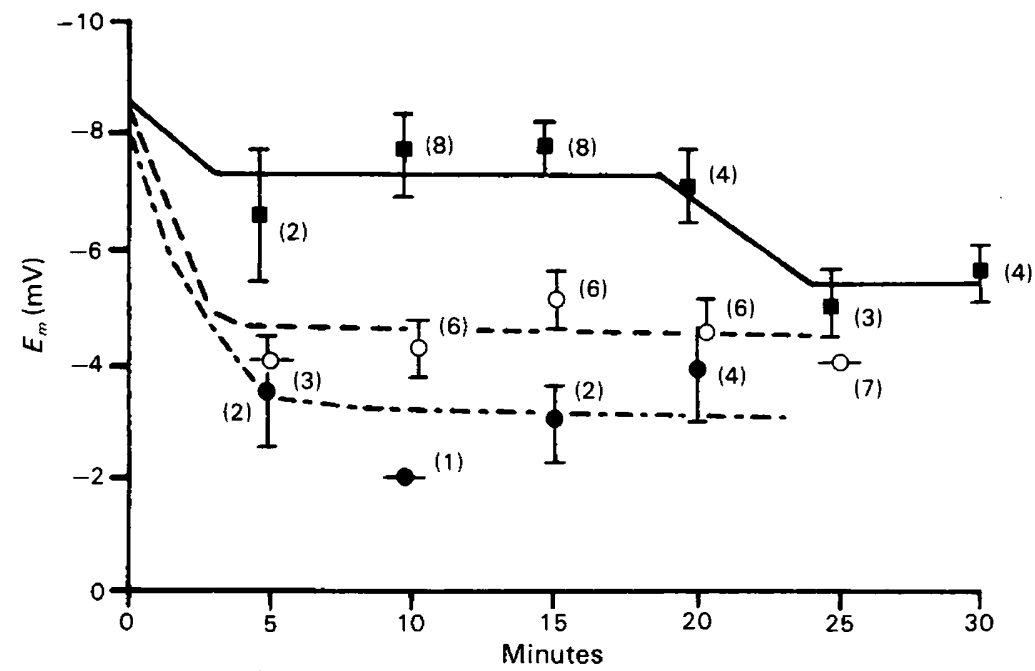

Text-fig. 1. The effect of ouabain on membrane potential $\left(E_{m}\right)$ in fresh ejaculated bull spermatozoa in medium containing $10^{-6} \mathrm{M}$-ouabain (D), $10^{-4} \mathrm{M}$-ouabain (O) or $10^{-3} \mathrm{M}$-ouabain (O). Values are mean \pm s.e.m. and figures in parentheses indicate the number of replicates. The $E_{m}$ measurements were averaged over 5-min intervals. 
The decline in membrane potential measured with microelectrodes when sperm cells were exposed to increasing concentrations of ouabain was associated with changes in intracellular potassium and sodium. Mean \pm s.e.m. intracellular potassium decreased from $20.1 \pm 1.2 \mathrm{mM}$ $(n=19)$ for cells in the control medium to $19.4 \pm 1.4 \mathrm{mM}(n=18)$ in $10^{-6} \mathrm{M}$-ouabain and to $14 \cdot 1$ $\pm 0.4 \mathrm{mM}(n=12)$ in $10^{-4} \mathrm{M}$-ouabain. Intracellular sodium increased from $106 \pm 12 \mathrm{~mm}$ in cells suspended in Mann's medium to $115 \mathrm{~mm}$ in cells suspended in $10^{-4} \mathrm{M}$-ouabain. These changes in potassium or sodium were not statistically significant.

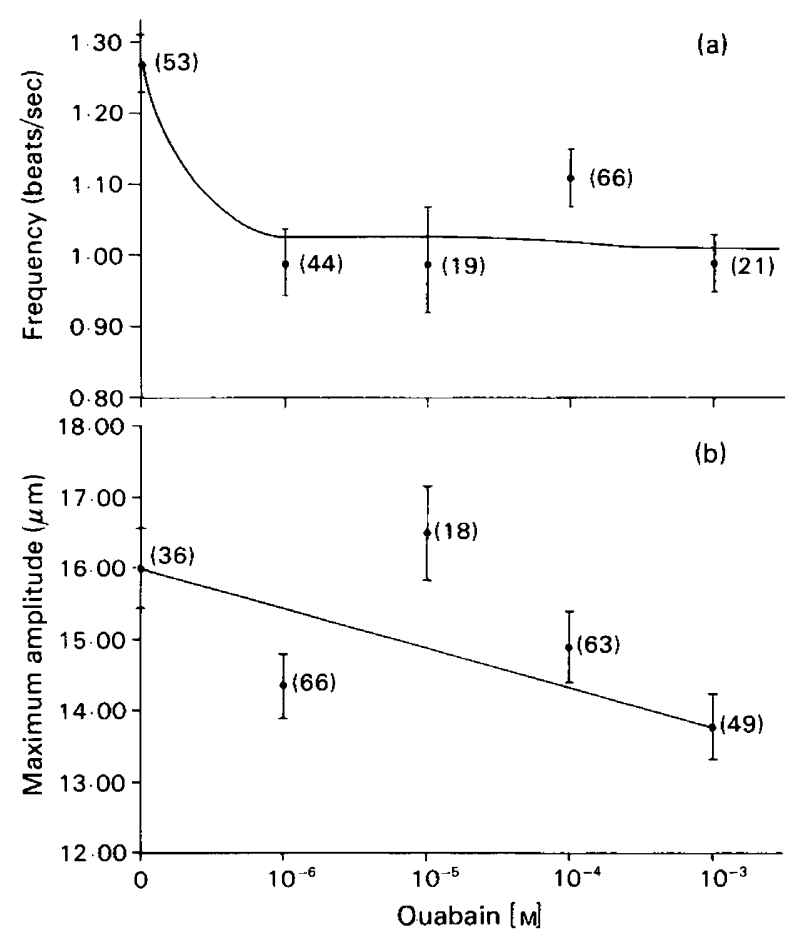

Text-fig. 2. The effect of ouabain on motility ( $a$, beat frequency; $b$, maximum amplitude of flagellar wave) of fresh bull spermatozoa suspended in Mann's medium with $1.5 \%$ methyl cellulose and $10^{-6}-10^{-3} \mathrm{M}$-ouabain. Values are mean \pm s.e.m. and figures in parentheses indicate the number of replicates.

The effect of ouabain on motility involved a change in progressive motility as well as frequency and amplitude of the flagellar wave. Progressive motility of cells suspended in Mann's medium with $10^{-3} \mathrm{M}$-ouabain declined within $30 \mathrm{~min}$ to $43 \%$ of control (set at $100 \%$ ). As shown in Text-fig. $2 \mathrm{a}$, increasing concentrations of ouabain $\left(10^{-6} \mathrm{M}\right.$ to $10^{-3} \mathrm{M}$ resulted in a decline in beat frequency from $1.27 \pm 0.16$ beats/sec (control) to $0.901 \pm 0.059\left(10^{-6} \mathrm{M}\right.$-ouabain). Higher concentrations of ouabain produced no further decline. Statistical analysis (ANOVA) showed that frequencies in ouabain-modified media were significantly different from that in control medium $(\alpha=0.01)$. Maximum amplitude of the flagellar wave was also affected by different concentrations of ouabain (Text-fig. 2b). Cells in ouabain-modified media taken collectively were significantly different from control $(16 \mu \mathrm{m})$ (independent $t, \alpha=0.0005$ ). There were no time-dependent changes observed in frequency or in amplitude up to $30 \mathrm{~min}$ of incubation. When spermatozoa were suspended in $10^{-6}$ or $10^{-3} \mathrm{M}$-ouabain and re-suspended in control medium, there was a continued effect of ouabain and no return to control values. 


\section{Discussion}

These results indicate that the cardiac glycoside ouabain, acting on $\mathrm{Na}^{+}-\mathrm{K}^{+}$-activated ATPase, affects the membrane potential and motility of ejaculated bull spermatozoa. Membrane potential declined as the concentration of ouabain increased, presumably due to the inhibition of active transport. This was predictable from (1) the existence of a metabolism-dependent concentration gradient for potassium $\left(\mathrm{K}_{\mathrm{in}}>\mathrm{K}_{\text {out }}\right.$ ) in ejaculated bull spermatozoa (Quinn \& White, 1968); (2) the dependence of membrane potential on the potassium gradient, i.e. intracellular/extracellular (McGrady \& Nelson, 1972); and (3) the decrease in intracellular potassium induced by ouabain.

Rink (1977) calculated the membrane potential $\left(E_{m}\right)$ to be $+13 \mathrm{mV}$ using the equation,

$$
E_{m}=\frac{R T}{\mathrm{nF}} \ln \frac{[\mathrm{K}]_{0}}{[\mathrm{~K}]_{\mathrm{i}}}
$$

The value for $[\mathrm{K}]_{0}$ was 75 mequiv./1 in the suspending medium. However, the measurement of intracellular potassium by flame photometry was made after centrifugation through a potassium and sodium-free medium, and $\left[\mathrm{K}_{\mathrm{i}}\right\rfloor$ was 45 mequiv./l. It is known that when spermatozoa are exposed to low potassium, and/or low sodium, the intracellular concentrations of these ions change dramatically (Blackshaw, 1953; Dott \& White, 1964; McGrady \& Nelson, 1973). Therefore, $[\mathrm{K}]_{0}$ was probably much lower than 75 mequiv./l, while the value determined for $[\mathrm{K}]_{\mathrm{i}}$ was the result of exposure to low $[\mathrm{K}]_{0}$ medium. In the present study determinations of intracellular potassium and sodium were made on cells suspended in Mann's medium in which there was $7.3 \mathrm{~mm}$-potassium and $143 \mathrm{~mm}$-sodium.

The effects of ouabain on motility reflected a generalized inhibitory action. Progressive motility of the population decreased to $43 \%$ of the control value. Beat frequency declined in cells suspended in $10^{-6}-10^{-3} \mathrm{M}$-ouabain, and this may reflect an inhibitory action of ouabain similar to its action on heart rate. Membrane potential and maximal amplitude of the flagellar wave were previously found to be related in ejaculated bull spermatozoa (McGrady \& Nelson, 1973): a partly depolarized spermatozoon, caused by manipulating the extracellular concentrations of potassium and sodium, generated flagellar waves of decreased amplitude. While the values obtained in the present study for spermatozoa suspended in the control medium and $10^{-6} \mathrm{M}^{-}$ ouabain agree with those predicted (McGrady \& Nelson, 1973), the values obtained at $10^{-4}$ and $10^{-3} \mathrm{M}$-ouabain were less than predicted. It appears that modification of membrane potential via inhibition of active transport has less pronounced effects on wave amplitude than modification by varying ion concentration.

When the spermatozoa were resuspended in Mann's medium after incubation in $10^{-6}$ or $10^{-3}$ M-ouabain, neither frequency nor amplitude returned to control values. This agrees with the finding of O'Donnell \& Ellory (1970) that $\left[{ }^{3} \mathrm{H}\right]$ ouabain was irreversibly bound to bull spermatozoa.

Nelson (1972) reported that ouabain produced concentration-dependent stimulatory or inhibitory effects in Arbacia spermatozoa: $10^{-7}$ and $10^{-6} \mathrm{M}$-ouabain increased motility to $120 \%$ of control whereas $10^{-4} \mathrm{M}$-ouabain decreased motility to $80 \%$ of control. In the present study, no stimulatory effects were observed. Bredderman \& Foote (1971) and Boender (1976) reported that fresh bull spermatozoa showed a decrease in progressive motility when incubated in solutions containing ouabain. The results in the present study identify the motility change induced by ouabain as a specific decrease in frequency and flagellar wave amplitude in addition to confirming the decrease in progressive motility.

I thank Denise Meschke, Cynthia Naumoff and Fernando Crotte for expert technical assistance and Dr L. Nelson for review of the manuscript. Bull semen was generously supplied by Select Sires, Inc. (Dr H. Kelgrin) and Northwest Ohio Breeders Association (Dr B. W. Kagy). This work was supported by NIH Research Grant No. HD09710. 


\section{References}

Blackshaw, A. (1953) The effects of potassium and calcium salts on the motility of ram, rabbit and bull spermatozoa. J. Physiol., Lond. 120, 465.

Boender, J. (1976) The relation between sperm quality and the effects of ouabain on the motility of spermatozoa. Tijdschr. Diergeneesk. 101, 11341140.

Bredderman, P.J. \& Foote, R.H. (1971) Alteration of cell volume in bull spermatozoa by factors known to affect active cation transport. Expl Cell Res. 66, 190-196.

Brody, T.M. (1974) Ouabain induced inhibition of cardiac $\left(\mathrm{Na}^{+} \mathrm{K}^{+}\right)$ATPase and the positive inotropic response. Ann. N.Y. Acad. Sci. 242, 684-687.

Dott, H. \& White, I. (1964) Effect of $\mathrm{K}^{+}$on ram spermatozoa studied by a flow dialysis technique. $J$. Reprod. Fert. 7, 127-138.

Lindeman, C. \& Rikmenspoel, R. (1971) Intracellular potentials in bull spermatozoa. J. Physiol., Lond. 219, 127-128.

Mann, T. (1964) Biochemistry of Semen and the Male Reproductive Tract, 2nd edn, p. 347. Methuen, London.

McGrady, A.V. \& Nelson, L. (1972) Cationic influences on sperm biopotentials. Expl Cell Res. 73, 192-196.

McGrady, A.V. \& Nelson, L. (1973) Electrophysiology of bull spermatozoa: correlations with motility. Expl Cell Res. 76, 349-352.

Nelson, L. (1954) Enzyme distribution in fragmented bull spermatozoa. Biochem. biophys. Acta 14, 312320.

Nelson, L. (1972) Quantitative evaluation of sperm motility control mechanisms. Biol. Reprod. 6, 319324.

O'Donnell, J.M. (1969) Intracellular levels of $\mathrm{Na}$ and $\mathrm{K}$ in bull spermatozoa in relation to cell metabolism. $J$. Reprod. Fert. 19, 207-209.

O'Donnell, J.M. \& Ellory, J.C. (1970) The binding of cardiac glycosides to bull spermatozoa. Experientia 26, 20-21.

Quinn, P.J. \& White, I.G. (1968) The transport of cations by ram and bull spermatozoa. Austr. J. biol. Sci. 21, 781-787.

Rink, T.J. (1977) Membrane potential of guinea-pig spermatozoa. J. Reprod. Fert. 51, 155-157.

Uesugi, S. \& Yamazoe, S. (1966) Presence of $\mathrm{Na}^{+} \mathrm{K}^{+}$ stimulated ATPase in boar epididymal spermatozoa. Nature, Lond. 209, 403-404.

Received 17 October 1978 